\section{Exceptional bonding, exceptional value}

For exceptional bonding with a high-quality, good value product, COLTENE recommends choosing ONE COAT 7 UNIVERSAL.

This award-winning agent can be used with self-etch, selective etch and total-etch techniques, on enamel and dentine.

ONE COAT 7 UNIVERSAL has many benefits including a low evaporation formula, superior marginal integrity and a userfriendly bottle, which means no waste due to the unique design.

ONE COAT 7 UNIVERSAL is just part of COLTENE's restorative range, developed through collaboration with specialists. With a commitment to innovation and improvement, COLTENE says it will give you the best results every time.

More information is available by visiting www.coltene.com, emailing info.uk@coltene.com or calling 01444235486.

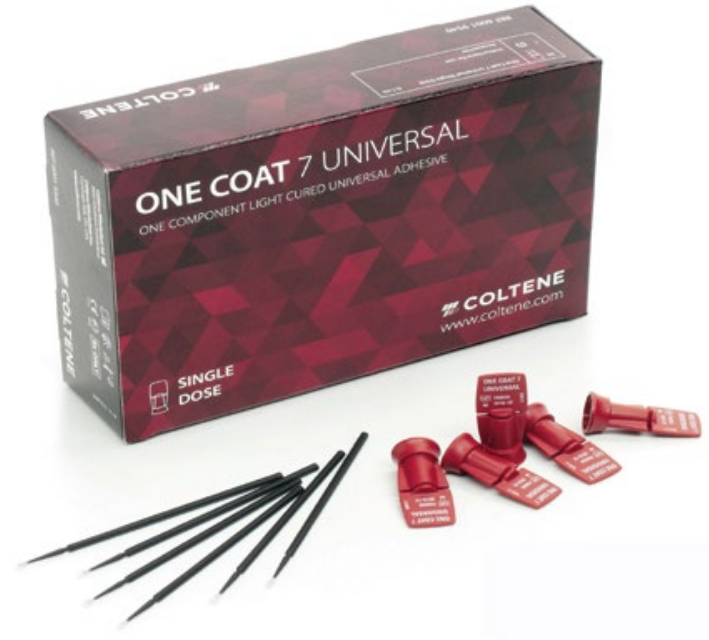

\title{
Dental products company named one of the 2019 World's Most Ethical Companies
}

Henry Schein, Inc, the world's largest provider of healthcare products and services to office-based dental and medical practitioners, has been recognised by the Ethisphere Institute - a global leader in defining and advancing the standards of ethical business practices - as one of the 2019 World's Most Ethical Companies.

This is the eighth consecutive year that Henry Schein has been recognised, and it is the only honouree in the healthcare products industry, underscoring the company's commitment to delivering the solutions healthcare professionals rely on to improve the performance of their practice so they can improve the lives of patients.

In 2019, 128 honourees were recognised spanning 21 countries and 50 industries.

The 13th class of honourees profoundly illustrates how companies continue to be the driving force for improving communities, building capable and empowered workforces, and fostering corporate cultures focused on ethics and a strong sense of purpose.
Stanley Bergman, Chairman of the Board and Chief Executive Officer of Henry Schein, said: 'Throughout our 87-year history, Henry Schein has been committed to pursuing our business goals with integrity while also serving the needs of society.

'We are honoured to once again be recognised as one of the Ethisphere Institute's World's Most Ethical Companies. This recognition reinforces our commitment to the concept of enlightened self-interest and our 'higher ambition' model of deep, trust-based partnerships. I am honoured to share this award with the more than 18,000 Team Schein Members around the world.'

Ethisphere's Chief Executive Officer Timothy Erblich, said: 'Henry Schein has demonstrated that corporate success and positive societal impact go hand-in-hand when an organisation aligns its strengths as a business with the needs of society. Congratulations to Team Schein for once again being named a World's Most Ethical Company'

The full list of the 2019 World's Most Ethical Companies can be found at https://worldsmostethicalcompanies.com/honorees.

\section{Improving men's oral health}

Inspire more men to seek the benefits of good oral health, great looking teeth and fresh breath with CB12 White.

CB12 White mouthwash enhances the oral hygiene routine, prevents oral malodour and brightens the teeth. As an adjunct to brushing and flossing, it helps to rinse away debris and bacteria and contains active ingredients that prevent unpleasant smelling breath for up to 12 hours.

It also has anti-plaque agents and fluoride to strengthen the teeth along with the technology to lift tooth stains and prevent new stains from developing. Used twice a day for two weeks, CB12 White produces a pleasing whitening effect that patients are sure to find appealing.

More information about CB12 and how it could benefit patients is available by visiting http://www.cb12.co.uk/.

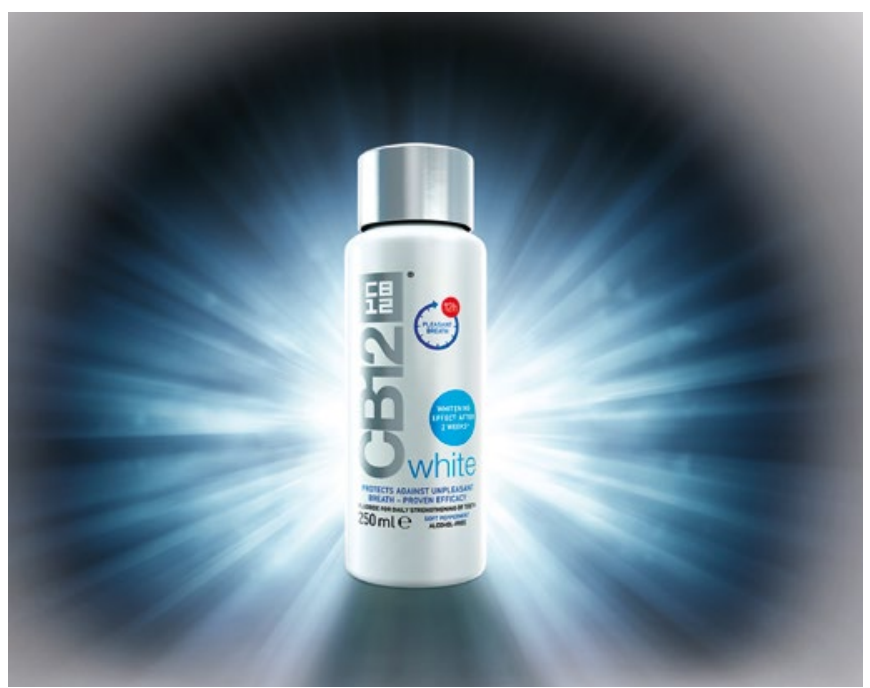

